\title{
Relationship between Short Term Memory and Cardiopulmonary Fitness of Administrative Officers at Universitas Padjadjaran
}

\author{
Iswaran Ampalakan, ${ }^{1}$ Ambrosius Purba, ${ }^{2}$ Sunaryo B. Sastradimaja ${ }^{3}$ \\ ${ }^{1}$ Faculty of Medicine Universitas Padjadjaran, ${ }^{2}$ Department of Physiology Faculty of Medicine \\ Universitas Padjadjaran, ${ }^{3}$ Department of Physical Medicine and Rehabilition, Faculty of Medicine \\ Universitas Padjadjaran/Dr. Hasan Sadikin General Hospital Bandung
}

\begin{abstract}
Background: The work of administrative officers depends a lot on their capability in memorizing. Increased fitness is strongly associated with a better memory. This study was conducted to determine the relationship between cardiopulmonary fitness and short term memory.

Methods: This analytical cross sectional study was carried out from August to September 2014. Subjects from administrative offices within Universitas Padjadjaran were chosen by simple random sampling. 101 individuals were selected, comprising of 68 males and 33 females. Data were obtained through Digit Span Test for short term memory and the cardiopulmonary fitness was measured using Harvard Step Test. The V02 Max obtained was correlated with the Digit Span Test score.

Results: The mean for cardiopulmonary fitness of males was found to be 36.1 , with standard deviation 8.63 , whereas mean cardiopulmonary fitness for females was found to be 32.94 , with standard deviation 7.5. For correlation analysis, the result of Spearman's rank analysis from the study showed that the p-value is 0.00 . Comparing to the significance level $\alpha=5 \%$, the $p$ value is worth less, thus the null hypothesis, Ho is rejected. Therefore, it could be concluded that there was a relationship between cardiopulmonary fitness and short term memory of male and female administrative officers at Universitas Padjadjaran.

Conclusions: There is a relationship between cardiopulmonary fitness and short term memory of male and female administrative officers at Universitas Padjadjaran. [AMJ.2016;3(1):34-7]
\end{abstract}

Keywords: Administrative officers, cardiopulmonary fitness, short term memory

\section{Introduction}

In today's modern society, our daily routine is very much determined by administrative officers. Every day, it can be seen that not every administrative officer has the same efficacy when it comes to getting the job done. Some are much more diligent, yet some are just much sloppier. There are two possibilities that might be able to explain the reason behind this difference in behavior. One such reason is the individual's attitude, while the other is being a physiologic explanation. This study is conducted to determine the existence of a physiologic explanation.

Physical fitness plays an important role in maintaining an optimum function of the human body. The cardiopulmonary system and nervous system, along with the network of blood capillaries function more effective with an increased level of physical fitness. ${ }^{1}$ Increased physical fitness is associated with an increased short term memory, increased reaction time, decreased anxiety and also decreased stress levels. ${ }^{2}$ The human brain, capability of cognitive function is what makes all daily tasks possible. It keeps us alert and enables us to process information and make decisions. ${ }^{3}$ Attention and short term memory are a core part of the brains cognitive function. Two parts of attention helping the formation and storage of short term memory are protection and prioritization. Protection, as its name implies, protects the memory from being degraded. This enables the information said to be recalled again. Prioritization on the other hand, gives "importance" to the certain

Correspondence: Iswaran Ampalakan, Faculty of Medicine, Universitas Padjadjaran, Jalan Raya Bandung-Sumedang Km.21, Jatinangor, Sumedang, Indonesia, Phone: +6287822004607 Email: jhothiesvaren95@gmail.com 
information, which then makes this particular information to be stored with higher priority when it is compared to other information. ${ }^{4}$

There are three theories which support the fact that exercise affects cognitive function. These theories are increased blood flow and angiogenesis which leads to increased oxygen saturation, increase in brain neurotransmitters which facilitate information processing, and regulation of neurotrophins such as brain derived neurotrophic factor (BDNF) ${ }^{5,6}$

Many previous studies have compared the positive effects of fitness on cognitive function, which showing promising results. ${ }^{7,8}$ It also proved that older adults were less likely to develop dementia, if they exercised at least three times a week, thus, proving and association between exercise and cognitive were decline., ${ }^{9,10}$ By doing this research, the results may create the awareness about the importance of exercise. Hopefully, the stigma that exercise is only good for physical health can be corrected by providing valid proof that exercise is beneficial to both physical and mental health. This may help to create a more holistic and healthy individuals within the society. Besides, the results of this research may also provide the information for the decision makers that physical activity can influence the level of short term memory.

\section{Methods}

This cross-sectional study was conducted from August to September 2014, after obtaining clearance from the Health Research Ethics
Committee, Faculty of Medicine, Universitas Padjadjaran. Participants were selected based on simple random sampling method. A total 130 individuals were interviewed during this study. There were 20 individuals who refused to take part into this study, while 2 individuals dropped out from the study because they could not complete the inclusion criteria and 1 individual was excluded due to exclusion criteria. Administrative officers with a high school background within the age group 30-60years old were in the inclusion criteria. However, respondents currently or previously diagnosed with heart condition, psychological condition and/or neurodegenerative disorder were excluded as per exclusion criteria. Later, 6 individuals were excluded from this study due to unsuccessful completion of the Harvard Step Test. Respondents' name, age, gender, address, VO2 Max and digit span test score were recorded down throughout the study.

Harvard Step Test was used to determine the cardiopulmonary fitness of participants. The Astrand Ryhming Nomogram was then used to estimate V02 max from the result of Harvard Step Test. For male subjects within the age group 30-39 years old, cardiopulmonary fitness was considered to be 'fair' if the score was 23-30, 'average' if the score was 31-38, 'good' if the score was 39-48 and high if the score was more than 49. For male subjects within the age group 40-49 years old, cardiopulmonary fitness was considered as fair if the score was 20-26, average if the score was 27-35, good if the score was 36-44, and high if the score was above 45 . For male

Table 1 Characteristic of Respondents

\begin{tabular}{lcc}
\hline \multicolumn{1}{c}{ Characteristic } & Frequency, $\mathbf{~}$ & Percentage, $\%$ \\
\hline Gender & 68 & 67 \\
Male & 33 & 33 \\
Female & & \\
Age Interval & 53 & 52 \\
30-39 years old & 43 & 43 \\
$40-49$ years old & 5 & 5 \\
50-59 years old & & \\
V02 max score & 23 & 23 \\
Fair & 33 & 33 \\
Average & 32 & 32 \\
Good & 13 & 12 \\
High & & \\
\hline
\end{tabular}


Table 2 Cardiopulmonary Fitness of Administrative Officers

\begin{tabular}{lcccc}
\hline Gender & $\begin{array}{c}\text { Cardiopulmonary } \\
\text { Fitness }\end{array}$ & Mean & n & Std. Deviation \\
\hline \multirow{3}{*}{ Male } & Fair & 25.8 & 15 & 1.5 \\
& Average & 33.3 & 27 & 3.5 \\
& Good & 41.6 & 16 & 3.8 \\
& High & 50.4 & 10 & 3.2 \\
& Total & 36.1 & 68 & 2.6 \\
Female & Fair & 23.8 & 8 & 3.3 \\
& Average & 29 & 16 & 3.6 \\
& Good & 36.5 & 3 & 0.6 \\
\hline
\end{tabular}

subjects within the age group 50-59 years old, cardiopulmonary fitness was considered as fair if the score was 18-24, average if the score was 25-33, 'good' if the score was 3442 and 'high' if the score was above 43 . As for the female subjects within the age group of 30-39 years old, cardiopulmonary fitness was considered as fair if the score was 20-27, average if the score was 28-33, good if the score was 34-44 and high if the score was more than 45 . Female subjects within the age group 40-49 years old were considered to have a fair cardiopulmonary fitness if the score was 17-23, average if the score was 24-30, good if the score was 31-41, and high if the score was above 42 .

In addition to that, Digit Span test was used to determine the short term memory of participants. Subjects were told a series of eight numbers randomly, and were asked to repeat the numbers in the same exact sequence. Each participant was given two attempts. 1 point was given to each number repeated in the correct sequence. The raw score obtained was recorded.

To determine the relationship between cardiopulmonary fitness and short term memory, the VO2 max was then correlated with the raw score from Digit Span Test using SPSS
Window Version 15.0. Data were statistically analyzed using Spearman's Rank analysis. The result was considered statistically significant when $\mathrm{p} \leq 0.05$.

\section{Results}

Majority of the administrative officers, 27 out of all 68, had an average cardiopulmonary fitness. Only a small amount of them had a high cardiopulmonary fitness. Most of the female administrative officers, 16 out of 33 fall were under the good category. Similarly, only a small amount of female administrative officers had a high cardiopulmonary fitness (Table 2).

The average short term memory score of female administrative officers were higher than male administrative officers. Female administrative officers had an average memory score of 8.6, whereas the average memory score was only 7.9 for male administrative officers. It can also be seen that female administrative officers had a higher maximum score when it was compared to male administrative officers (Table 3).

To determine the relationship between short term memory and cardiopulmonary fitness of administrative officers, Spearman's

Table 3 Short Term Memory Score of Administrative Officers

\begin{tabular}{lccccc} 
& \multirow{2}{*}{ Mean } & $\mathbf{n}$ & \multicolumn{3}{c}{ Memory Score } \\
\cline { 4 - 6 } & & & Std. Deviation & Minimum & Maximum \\
\hline Male & 7.9 & 68 & 2.9 & 3.0 & 14.0 \\
Female & 8.6 & 33 & 2.6 & 5.0 & 16.0 \\
\hline
\end{tabular}


rank correlation analysis was used in this study.

Results of the calculation showed that the $\mathrm{p}$-value obtained was 0.000 . The test would reject $\mathrm{Ho}$ if the $\mathrm{p}$-value $<\alpha(0.05)$. When it is compared to the significant value $(\alpha) 5 \%$, the $p$-value was much smaller that Ho was rejected. According to that fact there is a relationship between short term memory and cardiopulmonary fitness of administrative officers at Universitas Padjadjaran. The value of Spearman's rank correlation coefficient (rs) was found to be 0.471 (Table 4).

\section{Discussion}

The result of this study is slightly stronger than the previous study conducted by Walter Swardfager et al. ${ }^{11}$ The correlation coefficient from the previous study was 0.281 , while in this study, the correlation coefficient was 0.471 . This can be due to several factors. Firstly, in the previous study, respondents were patients with Coronary Artery Disease, whereas in this study there were no respondents suffering with any coronary disease at the time. Thus, the healthier individuals could provide better results. Besides, one of the limitations in the previous study was a smaller sample size, using only 81 patients.

However, this study does not have a similar limitation. This is due to the fact that the number of respondents in this study is 101 , which is a larger quantity than the minimum sample size required. This gives a more precise correlation between short term memory and cardiopulmonary fitness. However, this study has its own limitations. The number of male respondents in this study outweighs the number of female respondents vastly. A balanced number of respondents between male and female administrative officers was failed to be achieved. This was due to the time constraint in completing this study. If there had been more time, a more precise selection could have been done to achieve a balanced number of respondents between both genders.

As a conclusion, this study proves that there is a relationship between cardiopulmonary fitness and short term memory in male and female administrative officers at Universitas Padjadjaran. It shows that short term memory is better in individuals with higher cardiopulmonary fitness. Therefore, based on the results obtained from this study, it is recommended that all administrative officers maintain a healthy lifestyle with proper physical activity. This way, they will be able to maintain, or even improve their short term memory.

\section{References}

1. Wisloff U, Ellingsen O, Kemi OJ. Highintensity interval training to maximize cardiac benefits of exercise training. Exerc Sport Sci Rev. 2009;37(3):139-46.

2. Erickson KI, Weinstein AM, Lopez OL. Physical activity, brain plasticity, and Alzheimer's Disease. Arch Med Sci. 2012;43(8):615-21.

3. Barrett KE, Barman SM, Boitano S, Brooks H. Ganong's Review of Medical Physiology, 24th Edition, New York: Mcgraw-hill; 2012.

4. Matsukura M, Luck SJ, Vecera SP. Attention effects during visual short-term memory maintenance. Percept. Psychophys. 2007;69(8):1422-34.

5. Erickson KI, Voss MW, Prakash RS, Basak C, Szabo A, Chaddock L, et al. Exercise training increases size of hippocampus and improves memory. Proc Natl Acad Sci U.S.A. 2011;108(7):3017-22.

6. Ploughman M. Exercise is brain food: the effects of physical activity on cognitive function. Dev Neurorehabil. 2008;11(3):236-40.

7. Anderson-Hanley C, Arciero PJ, Brickman AM, Nimon JP, Okuma N, Westen SC, et al. Exergaming and older adult cognition: a cluster randomized clinical trial. Am J Prev Med. 2012;42(2):109-19.

8. Chang Y, Labban J, Gapin J, Etnier J. The effects of acute exercise on cognitive performance: A meta-analysis. Brain Res. 2012;1453:87-101.

9. Larson EB, Wang L, Bowen JD, McCormick WC, Teri L, Crane $P$, et al. Exercise is associated with reduced risk for incident dementia among persons 65 years of age and older. Ann Intern Med. 2006;144(2):73-81.

10. Bherer L, Erickson KI, Liu-Ambrose T. A Review of the Effects of Physical Activity and Exercise on Cognitive and Brain Functions in Older Adults. J Aging Res. 2013;2013:657508.

11. Swardfager W, Herrmann N, Marzolini S, Saleem M, Kiss A, Shammi P, et al. Cardiopulmonary fitness is associated with cognitive performance in patients with coronary artery disease. J Am Geriatr Soc. 2010 Aug;58(8):1519-25. 